\section{TURN YOUR PRACTICE INTO A GREAT BUSINESS}

At this year's Dental Showcase, Software of Excellence (SoE) is showing practice owners and managers how they can boost their profitability, improve patient communication and become expert users of EXACT.

With practices already benefiting from the recall automation in EXACT v11, SoE is launching their automated diary use that enables afternoon appointment spaces to be filled each morning. Text messages are automatically sent to patients on the short-notice cancellation list, inviting them to book in that day. Positive responses go straight into EXACT, ensuring no appointments are wasted.

To help re-engage with lapsed patients, SoE's new Patient Reactivation Service focuses on patients who haven't visited a practice for two years. SoE contacts these patients on your behalf and books appointments straight into EXACT, a highly efficient service that offers a guaranteed return on investment.

Talk to SoE about their new Academy of Excellence, a new training programme based on the martial arts grading system that takes the whole dental team through role-specific training.

Visit stand L12 and discover how to turn your practice into a great business.

www.softwareofexcellence.com

\title{
REVAMPED WEB PORTAL FOR PATIENT REGISTRATION
}

As part of DPAS' flexible, comprehensive and effective support for dental practices, the dental plan provider will be launching an entirely revamped Web Portal at this year's Dental Showcase, along with an online patient registration facility.

Featuring a whole host of new functionality, the Web Portal allows DPAS clients to access and amend all relevant details relating to their plan and plan patients, with real-time reporting and intuitive software making plan performance tracking simple and efficient.

Because one size doesn't fit all, patients will now have the option to sign up to dental plans online. Whether they're in the practice or from the comfort of their own homes, DPAS' Web Portal will continuously be helping DPAS clients to attract more patients in this increasingly competitive environment.

As part of DPAS' continuing commitment to reducing its impact on the environment and in keeping with its ISO14001 accreditation, this online solution reduces paperwork for everyone, while also helping practices to promote their own green credentials.

To find out how the DPAS Web Portal can benefit your practice, visit stand F11 at Dental Showcase, call 01747870910 or visit www.dpas.co.uk.

\section{THE BEST AUTOCLAVES AT THE BEST PRICES}

Committed to providing all-inclusive, affordable decontamination solutions, Eschmann's professionalism is evident in its commitment to supporting UK dentistry.

Focussed on providing the best autoclaves, at the best prices and with an unsurpassed level of added value in the form of free installation, validation and verifiable CPD training available for all its equipment, the Eschmann team will be on hand to demonstrate why the company is trusted by nearly half of all dental practices throughout the UK.
A selection of the latest autoclaves, decontamination equipment and consumables will be on display, including the state-of-the-art SES 3000B LittleSister vacuum autoclave with a unique air detection system to ensure successful sterilisation conditions are always achieved.

To find out how you can ensure outstanding decontamination processes in your practice, while saving money every day, make sure you visit stand H19 at the BDIA Dental Showcase.

www.eschmann.co.uk

\section{EXPERT ADVICE IN INFECTION CONTROL}

Eschmann will be demonstrating the very latest technologies in the world of decontamination at this year's BDIA Dental Showcase.

Eschmann are currently supporting nearly half of dental practices in the UK. They are dedicated to advancing the way they work to meet the evolving demands of the profession, so dentists can be sure to receive the most affordable, reliable service possible.

Students and foundation dentists visiting

Eschmann's stand at BDIA Dental Showcase will have the opportunity to meet the team of experts and seek advice and information in infection control. You will also have the chance to discover the array of cutting- edge equipment and products now available for exceptional decontamination procedures in practice. Learn how you can use such tools to ensure the safety of your patients and colleagues, as well as your compliance with regulations.

Amongst the state-of-the-art equipment on display will be the LittleSister SES 3000B autoclave, representing the latest in Eschmann's highly popular series. Hear from the experts how the vacuum autoclave's unique post sterilisation air detection guar- antees sterility and discover for yourself the benefits of features such as the user-friendly and intuitive touch screen.

Also on Eschmann's stand will be their new range of decontamination consumable products, designed to deliver a consistently high performance while saving you money. From sprays to wipes and liquids, Eschmann now offer a complete solution for all your decontamination needs.

To find out more, visit stand H19 at Dental Showcase. 